\title{
The barriers of responsible agriculture supply chain: The relationship between organization capabilities, external actor involvement, and supply chain integration
}

\author{
Irayanti Adriant $^{\mathrm{a}^{*}}$, Togar M.Simatupanga and Yuanita Handayati ${ }^{\mathrm{a}}$
}

\begin{tabular}{l}
${ }^{a}$ School of Busisness and Management, \\
\hline C H R O N I C L E \\
\hline Article history: \\
Received October 28,2020 \\
Received in revised format \\
January, 15, 2021 \\
Accepted February 82021 \\
Available online \\
February 82021 \\
\hline Keywords: \\
Responsible Supply Chain \\
Agriculture, barrier analysis \\
Integration \\
Organization Capabilities
\end{tabular}

\section{Introduction}

Sustainability is highly important in the context of agricultural supply chain, and often explained in terms of three sectors, economic, social, and environmental factors (Elkington, 1994). In order to achieve sustainability, an agricultural supply chain must not only pay attention to demand uncertainty, shipping route optimization, as well as inventory level optimization, and determine the optimal storage location for perishable products (Onggo et al., 2019; Diabat et al., 2019), but also consider the social aspect, and ensure the process has little negative impact on the environment and also. The risk factors in agriculture, particularly in perishable supply chains, are greater compared to non-perishable goods, due to the characteristic short shelf life and susceptibility to damage, forcing all supply chain members to consider sustainable action (Deng, 2019). A responsible agriculture supply chain is a part of sustainability focused on social and environmental consideration. This has been categorized into human rights (Panda, 2014; Plambeck and Toktay, 2015; Panda et al., 2017), food security and nutrition (Guo, 2015; Fan et al., 2019), technology and innovation (Camilleri, 2017), environmental protection and sustainability of natural resources (Kerekes \& Szegedi, 2012; Ye et al., 2018), and governance (Panda, 2017; Yan, et al., 2017; Nematollahi, 2017), by several related studies.

* Corresponding author

E-mail address: Irayanti-adriant@sbm-itb.ac.id (I. Adriant)

(C) 2021 by the authors; licensee Growing Science.

doi: $10.5267 /$ j.uscm.2021.2.003

\begin{abstract}
Responsible Supply Chain (RSC) has become an important issue in the agricultural supply chain, along with the development of the sustainable agriculture concept. Furthermore, responsible agriculture helps to ensure the availability of food and maintain land quality, enabling the land
to last for a long time. However, in practice, creating a responsible agricultural supply chain is rather difficult, especially in developing countries, where numerous barriers hinder the implementation of RSCs. This study therefore is an exploratory research aimed at finding the barrier factors to implementing responsible action in the agricultural supply chain. Multiple Case dady research methods were conducted to provide answers to the research question. Meanwhile, interpretive Structural Modelling was used to analyse the data obtained. The results showed the barrier factors faced in implementing responsible action within the agricultural supply chain include poor organizational capabilities, external actor involvement, and lack of supply chain and organizational policy, play a significant role in implementing a responsible agriculture supply chain. This Implementation is also highly dependent on external involvement by government or non-government organizations (NGOs), as some supply chains take responsible action because of obligations or pressure from these organizations. Another barrier is inadequate
supply chain integration, including integration, information sharing, and incentive alignment among supply chain members. Meanwhile, inadequate budget management, as part of organizational capabilities, is the major barrier giving rise to other challenges. The results of this study serve as a reference for supply chains, especially in the agriculture industry, while creating programs in a bid to reduce these inhibiting factors, to ensure responsible actions are well implemented well and able to provide a competitive advantage for all supply chain members.
\end{abstract}

C 2021 by the authors; license Growing Science, Canada. 
Currently, there is an increasing need for responsible supply chain and public knowledge on the importance of responsible action in business. Responsible actions as a part of achieving supply chain sustainability, provide benefits, including improved company image, reduced costs in the long run, increased revenue, and competitive advantage, to members of the supply chain (Hoejmose et al., 2014). However, despite the benefit of responsible action in the agricultural supply chain, RSC practices are rarely implemented. The welfare of farmers, as agricultural product suppliers, is often ignored by other supply chain members. These farmers sometimes bear all the costs and risks of agricultural cultivation, and consequently, make lower income, compared to the other supply chain members. Therefore, creating a responsible agricultural supply chain is important because there are many benefits to be gained by all the supply chain members. For farmers, a responsible supply chain considers the social aspects of farming activities, and improves welfare. This in turn guarantees quality of agricultural product supply. However, creating an agricultural supply chain is not easy. Only a few RSC studies are conducted in the field of agriculture, but these researches are crucial for creating improved conditions for all supply chain members. This is because very often, farmers as tier-1 suppliers do not receive the same added value as retailers and other members. The implementation of responsible action in the agricultural supply chain is difficult due to the numerous barriers faced. A study by Kerekes and Szegedi (2012) described responsible supply chain management as the key component of corporate social responsibility, proposing several challenges in RSC activities, including the difficulty of building integration between supply chain members, as well as, transparency, and accountability. Majority of the research conducted to analyze the barriers of implementing responsible agriculture supply were performed using quantitative methods (Faisal, 2012; Da Silva, et al., 2018). This study therefore aims to discuss from these barriers from the qualitative point of view. The study purpose is to explore the factors influencing the implementation of responsible supply chain practices in agriculture. This study will therefore deeply elaborate on the barriers factors in a bid to discover why responsible action is currently not well implemented in the agricultural supply chain. In addition, this research also discusses the relationship between those barriers. The results of this study serve as guideline for implementing RCS in the agricultural industry.

The following section provides a brief literature review of the barriers and facilitators of the responsible agriculture supply chain, while Section 3 describes the research methods used in the study. Meanwhile, Sections 4, 5, and 6 are designated to the results of data analysis using interpretive structural modeling, discussions and conclusions, respectively.

\section{Literature review}

\subsection{Responsible Agriculture Supply Chain}

The concept of sustainable supply chain management is often discussed from three aspects, economic, social, and environmental aspects, otherwise known as the three bottom line concepts (Elkington, 1994). A responsible supply chain is a supply chain must consider the social and environmental aspects of all supply chain activities, and serves a strategy for several companies to create a competitive advantage (Zakir et al., 2016). The benefits of responsible action for companies include cost reduction in the long run, new market opportunity, customer satisfaction, and increased profitability. However, despite these benefits, numerous barriers are faced while practicing responsible supply chain management. These include inadequate knowledge, cost-related issues, inadequate government support, absence of incentives for green practice, as well as sharing of information and technology sharing (Kumar \& Rahman, 2015). According to Hoejmose (2013), a responsible supply chain has a significant influence on a company or a supply chain's reputation. A study by Boerjonsen (2013) explored the importance and interrelation of organizational characteristics (for instance, ownership and size), and reported commitment and capabilities were arguably of key importance for RSCM. Meanwhile, Panda (2014) and Biswas et al. (2018), stated integration was also a key factor for responsible action. The implementation of RCS occurs not only at the operational level, but also at the level of tactic and strategy (Vaaland, et al., 2012), and the commitment of all internal stakeholders is necessary to achieve the goal of a responsible agriculture supply chain (Yawar and Seuring, 2018). In addition, most companies practice responsible supply chain management because of pressure from external stakeholders, including non-government organizations, customers, the community, and the government. In the agricultural sector, FAO has issued guidelines for measuring the level of the responsible supply chain, in order to assist companies in analyzing the implementation standards of responsible supply chains.

\subsection{Barriers and facilitators in implementing responsible agriculture supply chain}

The implementation of responsible supply chain management is not an easy process. Ozcelik and Ozturk (2014) reported organizational culture as an obstacle in practicing responsible supply chain management. A supply chain is a system consisting of several companies, therefore, cultural differences between companies leads to inequality in perceptions of the definition and the importance of an RCS. Also, companies incorporated in a supply chain often do not know about the need for responsible action. The benefits of responsible action, including corporate resilience, increased revenue, public trust, improved company image and consequent competitive advantages, are initially not directly experienced, but often felt in the long run (Kumar \& Rahman, 2015). Previous research almost pseudo-mention the problem of cost as the main barrier faced in responsible supply chain implementation. This is because responsible action requires substantial costs, and almost all companies allocate funds for responsible activity depending on the profit generated (Kumar \& Rahman, 2015; Ozcelik 
\& Ozturk, 2014; Tay, 2015; Szegedi 2012). Responsible actions are also facilitated by several factors, including government policy and pressure from investors (Tay, 2015). However, some companies act responsibly not because of awareness, but because of encouragement from outsiders.

The implementation of RSC management is also strongly influenced by the extent of collaboration on the part of supply chain members. Therefore, proper communication and sharing of information allows for better integration within the supply chain, consequently, facilitating responsible action.

\section{Research methodology}

This study used qualitative research methods because the study aims to elaborate on the factors influencing the implementation of RSC, especially in the agricultural sector. The responsible agriculture supply chain is a system consisting of not only material items, including agriculture products, but also concerned with the dynamic behavior of humans (actor). According to Cresswell (2014), qualitative research is a process of study and understanding, based on a methodology investigating a social phenomenon and a human problem. In this approach, the researcher generates a complex, detailed reports, including pictures, from the respondents' point of view, and conducts studies on the natural situation. Therefore, this study uses an explanatory approach, because the objective is to investigate phenomena in real-life contexts, and the boundaries between phenomena and contexts are not explicit (Yin, 2014; Ha-Brookshire, 2017). Subsequently, data was collected from two agribusiness companies through observation and face-to-face interviews. The interview were is semistructured, with a total of 63 questions, while the interviewees were selected based on the responsibilities in implementing the responsible action within the two companies, as well as an understanding of the organization's supply chain conditions. Through these interviews, a comprehensive understanding of the activities or and challenges involved in implementing a responsible agriculture supply chain, were obtained. The information obtained was then analyzed, using the Interpretive Structural Modeling approach.

\section{Interpretive Structural Modeling (ISM)}

ISM is a technique often used to analyze the relationship between variables, through interactive judgment from a group of experts. The steps of Interpretative Structure Modelling are outlined below.

\section{a. Identify the barrier factor}

From the study literature and interviews conducted during preliminary observation, 6 (six) barrier factors were concluded to hinder the implementation of responsible agriculture supply chain (Table 1).

Table 1

The Barriers factors of Responsible Agriculture Supply Chain Management

\begin{tabular}{cll}
\hline Barrier Number & \multicolumn{1}{c}{ Barrier description } & \multicolumn{1}{c}{ References/ observation } \\
\hline 1 & Lack of organizational capabilities & Kerekes and Szegedi (2012) \\
2 & Lack of Supply chain integration & Kamble (2019), Norrman (2019) \\
3 & Interdependencies to external factors & Observation \\
4 & Lack of budget management & Tay et al., (2015), Ozcelik and Ozturk (2014) \\
5 & Lack of incentive alignment & Lewis (2019), observation \\
6 & Lack of technological infrastructure & Kouhizadeh (2020) \\
\hline
\end{tabular}

b. Build the Structural self-interaction matrix (SSIM)

From the discussion with several experts in the companies, the relationship between these barrier factors were identified. The following four symbols were used to analyze the relationship between barriers ( $\mathrm{i}$ and $\mathrm{j}$ ).

$\mathrm{V}$ - barrier i will help to achieve barrier $\mathrm{j}$;

A- barrier j will help to achieve barrier $i$;

$\mathrm{X}$ - barrier $\mathrm{i}$ and $\mathrm{j}$ will help to achieve each other;

$\mathrm{O}$ - barrier $\mathrm{i}$ and $\mathrm{j}$ are unrelated

Table 2 shows the Structural self-interaction matrix of the RSC barrier.

Table 2

Structural self-interaction matrix (SSIM)

\begin{tabular}{|c|c|c|c|c|c|c|c|}
\hline \multirow[b]{2}{*}{ Barrier Number } & \multirow[b]{2}{*}{ Barrier description } & \multicolumn{6}{|c|}{ Barrier number } \\
\hline & & 6 & 5 & 4 & 3 & 2 & 1 \\
\hline 1 & Lack of organizational capabilities & A & $\mathrm{O}$ & A & $\mathrm{A}$ & $\mathrm{V}$ & $\mathrm{X}$ \\
\hline 2 & Lack of Supply chain integration & A & A & A & A & $\mathrm{X}$ & \\
\hline 3 & Interdependencies to external factors & $\mathrm{O}$ & $\mathrm{O}$ & A & $\mathrm{X}$ & & \\
\hline 4 & Lack of budget management & $\mathrm{V}$ & $\mathrm{O}$ & $\mathrm{X}$ & & & \\
\hline 5 & Lack of incentive alignment & $\mathrm{O}$ & $\mathrm{X}$ & & & & \\
\hline 6 & Lack of technological infrastructure & $\mathrm{X}$ & & & & & \\
\hline
\end{tabular}


The reachability Matrix was obtained from SSIM by substituting V, A, X, and $\mathrm{O}$ with 1 and 0 , using the rules outlined below.

- In cases where the $(i, j)$ entry in the SSIM is $V$, the $(i, j)$ entry in the reachability matrix becomes 1 , while the $(j$, i) entry becomes 0 .

- In cases where the (i, j) entry in the SSIM is A, the (i, j) entry in the reachability matrix becomes 0 , while the (j, i) entry becomes 1 .

- In cases where the (i,j) entry in the SSIM is X, the $(i, j)$ entry in the reachability matrix becomes 1 , while the $(j$, i) entry also becomes 1 ; and

- In cases where the (i, j) entry in the SSIM is $\mathrm{O}$, the $(i, j)$ entry in the reachability matrix becomes 0 , while the $(j$, i) entry also becomes 0 .

The issue of transitivity must be considered in building the reachability matrix, and all entries must be free transitivity errors. Table 3 shows the reachability matrix obtained by following the rules outlined above.

Table 3

$\underline{\text { Initial Reachability matrix }}$

\begin{tabular}{|c|c|c|c|c|c|c|c|}
\hline \multirow{2}{*}{$\begin{array}{l}\text { Barrier } \\
\text { Number }\end{array}$} & \multirow[b]{2}{*}{ Barrier Description } & \multicolumn{6}{|c|}{ Barrier number } \\
\hline & & 6 & 5 & 4 & 3 & 2 & 1 \\
\hline 1 & Lack of organizational capabilities & 0 & 0 & 0 & 0 & 1 & 1 \\
\hline 2 & Lack of Supply chain integration & 0 & 0 & 0 & 0 & 1 & 0 \\
\hline 3 & Interdependencies to external factors & 0 & 0 & 0 & 1 & 1 & 1 \\
\hline 4 & Lack of budget management & 1 & 0 & 1 & 1 & 1 & 1 \\
\hline 5 & Lack of incentive alignment & 0 & 1 & 0 & 0 & 1 & 0 \\
\hline 6 & Lack of technological infrastructure & 1 & 0 & 0 & 0 & 1 & 1 \\
\hline
\end{tabular}

\section{d. Perform Level Partitions}

The next step is to perform level partition useful for graph formation. Meanwhile, the reachability set and antecedent set were determined from the last reachability matrix. The reachability set comprises the main element, and others the element is able to achieve, while the antecedent set consist of the main element and others useful in achieving the element. Furthermore, the intersection, the common element of the reachability set and antecedent set, must also be determined. The process of determining the level is known as the iterative process, and the element is designated as the top-level element, in a case where the reachability set and intersection values are the same. Subsequently, this element is removed from the reachability matrix, and the second iteration is performed. Tables 4, 5, 6, and 7 show the Partition of the reachability matrix.

Table 4

Partition of reachability Matrix (first iteration)

\begin{tabular}{|c|c|c|c|c|}
\hline Barrier Number & Reachability Set & Antecedent set & Intersection & Level \\
\hline 1 & 1,2 & $1,3,4,6$ & 1 & \\
\hline 2 & 2 & $1,2,3,4,5,6$ & 2 & I \\
\hline 3 & $1,2,3$ & 3,4 & 3 & \\
\hline 4 & $1,2,3,4,5$ & 4 & 4 & \\
\hline 5 & 2,5 & 5 & 5 & \\
\hline 6 & $1,2,6$ & 4,6 & 6 & \\
\hline
\end{tabular}

Based on the table above, barrier number 2 was concluded to be the top-level barrier because the value of reachability is the same as the intersection. Therefore, the element 2 was removed from the table in the subsequent iteration. Table 5 shows the second iteration in partitioning the reachability matrix shown.

Table 5

Partition of reachability Matrix (second iteration)

\begin{tabular}{|c|c|c|c|c|}
\hline Barrier Number & Reachability Set & Antecedent set & Intersection & Level \\
\hline 1 & 1 & $1,3,4,6$ & 1 & II \\
\hline 3 & 1,3 & 3,4 & 3 & \\
\hline 4 & $1,3,4,5$ & 4 & 4 & \\
\hline 5 & 5 & 5 & 5 & II \\
\hline 6 & 1,6 & $3,4,6$ & 6 & \\
\hline
\end{tabular}


Table 6

Partition of reachability matrix (third iteration)

\begin{tabular}{lllll}
\hline Barrier Number & Reachability Set & Antecedent set & Intersection & Level \\
\hline 3 & 3 & 3,4 & 3 & \\
4 & 3,4 & 4 & 4 & \\
6 & 6 & $3,4,6$ & 6 & III \\
\hline
\end{tabular}

\section{Table 7}

Partition of reachability Matrix (fourth iteration)

\begin{tabular}{llll}
\hline Barrier Number & Reachability Set & Antecedent set & Intersection \\
\hline 4 & 4 & 4 & 4 \\
\hline
\end{tabular}

\section{e. Build the ISM Digraph and Model}

The last step of ISM is to build the ISM digraph and structural model from the initial reachability matrix. The top element barrier (level 1) will be at the top of the digraph, followed by levels $2,3,4,5$, and 6 . Figure 1 shows the final digraph obtained.

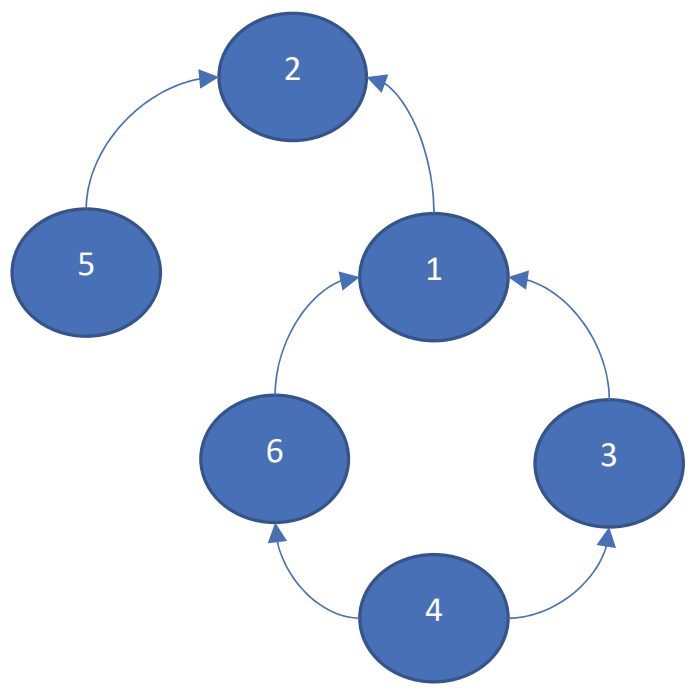

Fig. 1. Final digraph of the Relationship between the Barriers of Responsible Agriculture Supply Chain

Meanwhile, Fig. 2 shows the Interpretive Structure Modelling of the barriers of responsible agriculture supply chain.

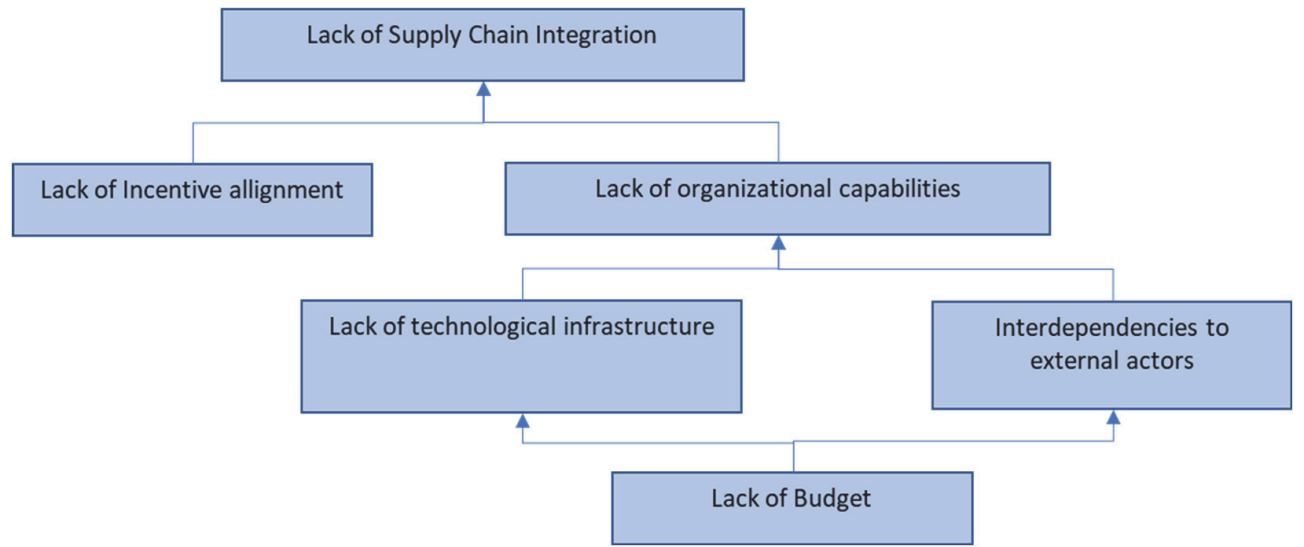

Fig. 2. The initial model of the Relationship between the Barrier Factors of Responsible Agriculture Supply Chain 
MICMAC is an acronym for Matriced Impact Croises-Multiplication Applique and Classment (cross-impact matrix multiplication applied to classification). This analysis aims to determine the position of each barrier against the system, from the driving power and individual dependence power. The four possible barrier positions include:

1. Autonomous: These barriers have weak driver and weak dependence powers, and are represented in the first quadrant.

2. Dependent: These barriers are characterized by weak driver power and strong dependence power, and are denoted in the second quadrant.

3. Independent: These barriers have strong driver power and week dependence power, and are represented in the third quadrant.

4. Linkage: These barriers are characterized by strong driver and strong dependence powers, and are denoted in the fourth quadrant.

Based on the results of MICMAC analysis (Fig. 3) three barriers, interdependencies to external factors, lack of incentive alignment and lack of technological infrastructure, fall into the autonomous category. This means these barriers have little impact on the implementation of responsible agriculture and have a weak relationship with the other barriers. In addition, two barriers, lack of organizational capabilities and lack of Supply chain integration fall into the dependent category. This means despite the little impact on RSC implementation, these barriers have a strong relationship with other barriers. Meanwhile, only one barrier, lack of budget management, is categorized as independent, meaning this is the main RSC implementation barrier, having a strong relationship with others. No barrier fell into the linkage category, meaning there was no dominant barrier.

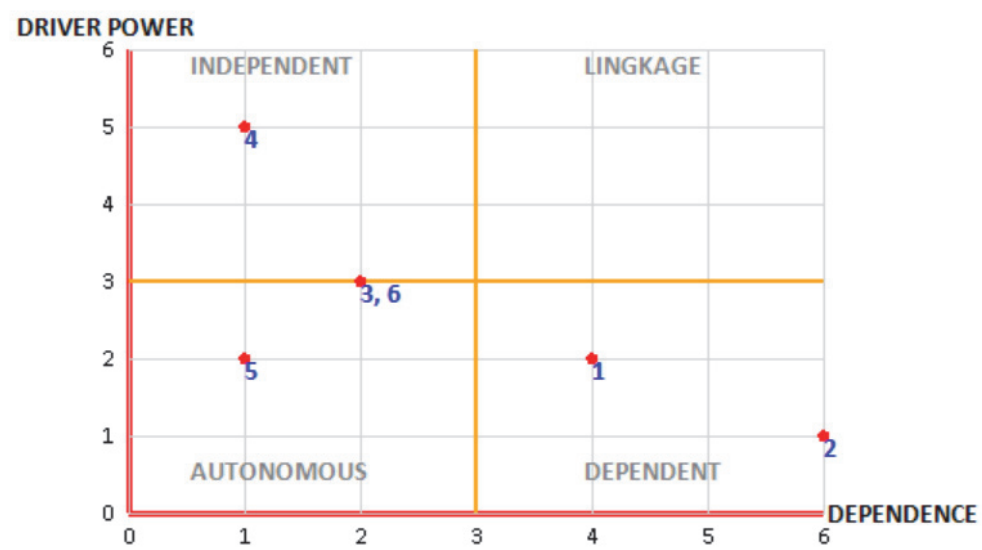

\section{Discussion}

Fig. 3. MICMAC Matrix

\subsection{The Role of External Actors in Responsible Supply Chain Implementation}

Responsible agriculture supply chain activity is sometimes motivated by the external actors, including the government or non-government organizations. The regulations issued by the government are often the basis for implementing responsible activities. However, the assistance rendered by the government in solving the social problems of companies is not currently well implemented. According to the manager of PT.A, "government owned companies are obligated to conduct responsible practices, especially Corporate Social Responsibility (CSR) programs". Non-governmental organizations are also significant parties in the process of controlling responsible practices in companies. This is crucial because NGOs often communicate and give control to companies to facilitate the sustainability of these companies. Furthermore, other stakeholders, including shareholders have a significant role in the implementation of responsible practices within companies, because shareholders are the most important decision-makers. However, the most common problem faced in this implementation is the constraints of a limited budget. Meanwhile, government owned organizations are more likely to ignore responsible practices compared to private companies, due to the lack of rigorous audit processes involved in operational activities. These private companies, especially after going public, pay close attention to responsible activities, and display the sustainability report on the company's website. This is very useful for increasing company image, and this in turn increases public trust and the number of shareholders. Responsible action in the agriculture supply chain is currently being conducted due to pressure from outside parties, and not because of consciousness. Thus, a low external pressure 
implies low implementation of responsible action. This finding is in line with the report by Faisal (2010) stating inadequate government regulations and standards is a barrier in the implementation of responsible action in companies.

\subsection{Organizational capabilities enrich the implementation of Responsible Supply Chain in Agriculture}

Organization capabilities refers to an organization's ability to identify, manage, and utilize all available resources in achieving desired objectives, including corporate sustainability (da Cunha Bezerra et al., 2020), and these determine the success in implanting a RSC. An organization's capabilities include cost management, knowledge management in terms of $\mathrm{RSC}$, organization policies and initiatives for responsible action. The issue of cost is a determining factor in the implementation of responsible practices within a government-owned company. Funding for CSR is dependent on the revenue generated, thus, the certainty of conducting responsible practices is extremely low. However, companies try to set aside budget for CSR programs, every year, no matter how small. According to the chief of operation PT.A "CSR is often implemented when the maximum profit is generated, but a bit disturbed in cases where a loss is experienced". The company has taken the initiative to conduct various activities in a bid to increase the social welfare of employees, even without an understanding of CSR. In terms of basic workers' rights, the company has performed quite well. However, training programs are required to improve the knowledge and skills of employees. This is because employees consider CSR as to be the only aspect of responsible practices, even though the term responsible has a broad meaning. These employees have even carried out responsible practices without being aware. Therefore, there is a need to equalize all employees' perceptions of the definition of responsible, so all workers have a complete understanding and the same reasons for acting responsibly. In addition, government-owned companies are unaware of the benefits of responsible practices, outside of employee welfare, including improved corporate image, and corporate sustainability. In this company, responsible practices are not a strategic problem, and this is shown by the absence of a special section to handle the responsible practices. The company is also unaware of standard responsible indicators. Sustainability is the goal of private companies, and this is shown by the existence of well-planned responsible programs, including eco-friendly practices or welfare suppliers, already included in the company's long-term goals. According to the Chief of operation, PT.B, "the sustainability of the program is well planned, and CSR has been used to improve supplier welfare in the policy regarding environmentally friendly activities. The public has also been provided with annual reports on the company's sustainable activity". This finding is in accordance with the report by Vaaland and Owusu (2012), stating responsibility supply chain ought to not only cover the technical aspect, but also be a core value of an organization, manifested in the company's policy and tactical strategy.

\subsection{Influence of Supply Chain Integration in Implementing Responsible Supply Chain}

Integration and collaboration within the supply chain are crucial in implementing a responsible agriculture supply chain. Based on the interview, the company currently lacks a mechanism for exchanging information with other supply chain members regarding RSC programs. Meanwhile, the implementation of CSR is not currently integrated between supply chain members, thus, there is no structured and integrated program. Furthermore, there is an unclear distribution of incentives for responsible activities among members of the supply chain. These incentives are only aligned while calculating the cost for responsibility (including cost of eco-friendliness or CSR), as a component in product price determination. Therefore, communication about responsible practices is limited to the company, as no comprehensive communication has been created for this purpose, between the manufacturers and suppliers or distributors. This is because no party is a designated leader a leader in the supply chain. Another barrier to implementing a responsible agriculture supply chain is the unwillingness to share information. This sharing is transactional, and no party will share without being assured of obtaining benefits. Therefore, this finding reinforces the report by Todeschini, et al., (2020) aswell as Khosravi and Izbirak (2019), stating a good stakeholder collaboration leads to better understanding and is useful in performing innovative action to achieve a sustainable supply chain. Meanwhile, Handayati, et al., (2015) in a study regarding coordination in the agri-food supply chain stated coordination between supply chain members, will improve performance, and de Matos (2013) reported the need for organizations to change in order to gain sustainability. Organization ought to quit thinking solely of generating profit, and make plans to save the environment and also contribute positively to the society.

In addition, brookeshire (2017) stated a supply chain is truly responsible if three conditions are fulfilled. Firstly, responsible action must be perfect or universal duty, all parties abide by it in every situation. Secondly, there must be clear and convergent organizational goals and lastly, all supply chain members must attention to the responsible aspects. Without all three conditions being fulfilled, responsible practices in a supply chain tend to be poorly implemented, and the results of this study corroborates these findings. Thus, one aspect of organizational capabilities is the ability to clearly define the organization's goals, and companies without responsible aspects of goals tend to act less responsibly, because initially organizational resources (including workers and capital) are not directed to act responsibly. However, organization capabilities are not sufficient because all supply chain members must also have the same goal. Therefore, integration is also needed between members of the supply chain. Figure 4 shows the four quadrants obtained from the relationship between organizational capabilities and supply chain integration in driving responsible action. 


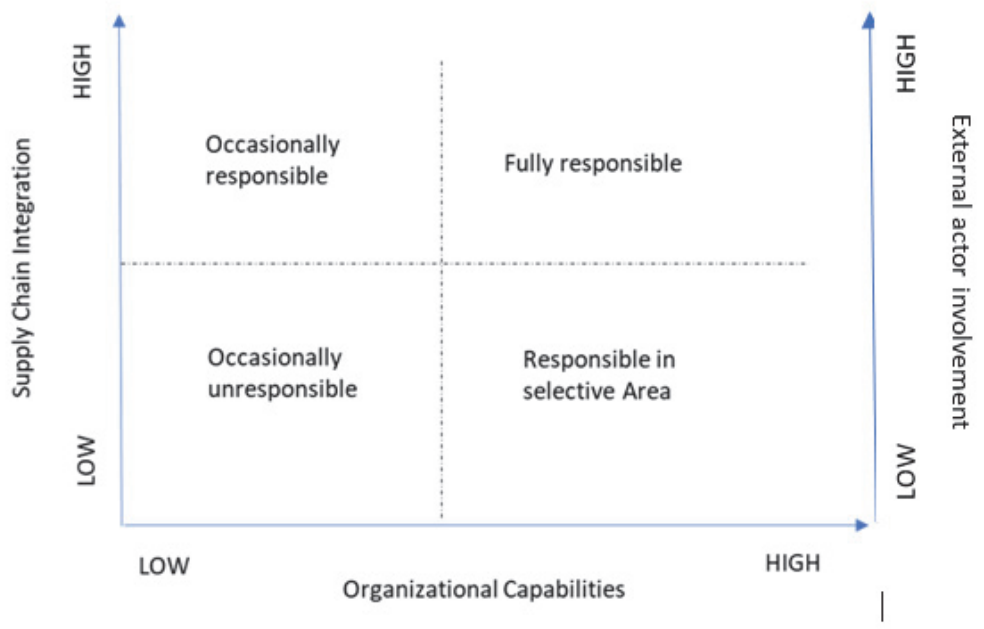

Fig. 4. The Relationship between Organization Capabilities and Supply Chain Integration, in driving responsible Action

Supply chain integration helps to responsible action as even organizations with low capability are able to act responsibly in the presence of supportive and well-integrated supply chain partners. This supply chain integration is made possible by sharing information regarding the benefits and motivation of responsible action, and by developing an incentive sharing scheme in cases where supply chain members are willing to act responsibly. Low level of integration within a supply chain, leads to one of two possibilities. An organization with low capabilities tends to act irresponsibly, however, one with high capabilities is able to act responsibly only in certain areas. These organizations are characterized by the presence of responsible programs, and conducting responsible actions, without involving other supply chain members. Furthermore, external actor involvement influences the responsible supply chain implementation. Initially, responsible action may be conducted because of necessity or pressure from external actors, however, the supply chain becomes accustomed to carrying out responsible action overtime, and in the end, becomes able to act responsibly from initiative.

\section{Conclusions and recommendations}

This paper has elaborated on the barrier factors of implementing a responsible agriculture supply chain. These include low organization capabilities, including cost management, knowledge management, company initiative and policy. Several companies fail to strategically plan responsible action, and this is shown by the absence of company policies relating to responsible practices. Consequently, employees are unaware of the importance and benefits of responsible action. In some companies, social action in not currently a necessity, and responsible action is highly dependent on the availability of funds and pressure from external actors. Inadequate supply chain integration is also another barrier in implementing a responsible agriculture supply chain, and the unwillingness to share information leads to miscommunication among supply chain members and consequently, lack of coordination. Another barrier factor is the absence of incentive alignment policies among supply chain members willing to conduct responsible practices, thus there is a need to create incentive schemes for these parties. The result of interpretive structural modeling showed lack of budget management is the main barrier an agriculture supply chain must consider prior to conducting responsible action. This barrier gives rise to others, including lack of information, infrastructure and incentive alignment. This paper also discussed the four quadrants of a responsible company based on the level of organization capabilities and supply chain integration. These two variables must therefore complement each other for a fully responsible company to be created.

\section{References}

Biswas, I., Raj, A., \& Srivastava, S. K. (2018). Supply chain channel coordination with triple bottom line approach. Transportation Research Part E: Logistics and Transportation Review, 115, 213-226.

Camilleri, M. A. (2017). The rationale for responsible supply chain management and stakeholder engagement. Journal of Global Responsibility, 8(1), 111-126. https://doi.org/10.1108/JGR-02-2017-0007

Cresswell, J. W. (2014). Research Design Qualitative, quantitative, and Mixed Methods Approaches. ${ }^{\text {th }}$ ed. SAGE Publication. ISBN 978-602-229-584-6

da Cunha Bezerra, M. C., Gohr, C. F., \& Morioka, S. N. (2020). Organizational capabilities towards corporate sustainability benefits: A systematic literature review and an integrative framework proposal. Journal of Cleaner Production, 247, 119114. 
De Silva, F. C., Shibao, F. Y., Barbieri, J. C., Librantz, A. F. H., \& SANTOS, M. R. D. (2018). Barriers to green supply chain management in the automotive industry. Revista de Administração de Empresas, 58(2), 149-162.

De Matos, J. A., \& Clegg, S. R. (2013). Sustainability and organizational change. Journal of Change Management, 13(4), $382-386$

Elkington, J. (1994). Cannibals with Forks: the Triple Bottom Line of 21st Century Business. Capstone, ISBN 1-900961$27-\mathrm{X}$

Faisal, M. N. (2010). Analysing the barriers to corporate social responsibility in supply chains: an interpretive structural modelling approach. International Journal of Logistics: Research and Applications, 13(3), 179-195.

Fan, K., Li, X., Wang, L., \& Wang, M. (2019). Computers \& Industrial Engineering Two-stage supply chain contract coordination of solid biomass fuel involving multiple suppliers. Computers \& Industrial Engineering, 135(January), 1167-1174. https://doi.org/10.1016/j.cie.2019.01.016

Guo, R., Lee, H. L., \& Swinney, R. (2016). Responsible sourcing in supply chains. Management Science, 62(9), 27222744.

Ha-Brookshire, J. (2017). Toward moral responsibility theories of corporate sustainability and sustainable supply chain. Journal of Business Ethics, 145(2), 227-237.

Handayati, Y., Simatupang, T. M., \& Perdana, T. (2015). Agri-food supply chain coordination : state-of-the-art and recent developments. Logistics Research, 8(1), 1-15. https://doi.org/10.1007/s12159-015-0125-4

Hoejmose, S. U., Grosvold, J., \& Millington, A. (2013). Socially responsible supply chains: power asymmetries and joint dependence. Supply Chain Management: An International Journal, 3(May 2012), 277-291. https://doi.org/10.1108/SCM-01-2012-0033

Khosravi, F., \& Izbirak, G. (2019). A stakeholder perspective of social sustainability measurement in healthcare supply chain management. Sustainable Cities and Society, 50, 101681. https://doi.org/10.1016/j.scs.2019.101681

Kumar, D., \& Rahman, Z. (2015). Sustainability adoption through buyer-supplier relationship across the supply chain: A literature review and conceptual framework. International Strategic Management Review, 3, Pp 110-127. http://dx.doi.org/10.1016/j.ism.2015.04.002

Nematollahi, M., Hosseini-motlagh, S., \& Heydari, J. (2017). Economic and social collaborative decision-making on visit interval and service level in a two-echelon pharmaceutical supply chain. Journal of Cleaner Production, 142, 39563969. https://doi.org/10.1016/j.jclepro.2016.10.062

Ozcelik, F., \& Ozturk, B. A. (2014). Research on barriers to sustainable supply chain management and sustainable supplier selection criteria. Sosyal Bilimler Enstitüsü Dergisi, 16(2), 259-279. DOI: 10.16953/deusbed.89025

Panda, S., Mohan, N., \& Cárdenas-barrón, L. E. (2017). Coordinating a socially responsible closed-loop supply chain with product recycling. International Journal of Production Economics, 188(July 2016), 11-21. https://doi.org/10.1016/j.ijpe.2017.03.010

Panda, S. (2014). Coordination of a socially responsible supply chain using a revenue-sharing contract. Transportation research Part E, 67, 92-104. https://doi.org/10.1016/j.tre.2014.04.002

Plambeck, E. L., \& Toktay, L. B. (2013). Introduction to the Special Issue on the Environment.

Kerekes, K. N., \& Szegedi, K. (2012). Challenges of responsible supply chain management. Theory, Methodology, Practice, 8(2), 68-72.

Tay, M. Y., Abd Rahman, A., Aziz, Y. A., \& Sidek, S. (2015). A review on drivers and barriers towards sustainable supply chain practices. International Journal of Social Science and Humanity, 5(10), 892.

Todeschini, B. V., Cortimiglia, M. N., \& de Medeiros, J. F. (2020). Collaboration practices in the fashion industry: Environmentally sustainable innovations in the value chain. Environmental Science \& Policy, 106, 1-11.

https://doi.org/10.1016/j.envsci.2020.01.003

Vaaland, T. I., \& Owusu, R. A. (2012). What is a responsible supply chain?. International Journal of Business and Management, 7(4), 154. http://dx.doi.org/10.5539/ijbm.v7n4p154

Yawar, S. A., \& Seuring, S. (2017). Management of social issues in supply chains : A literature review exploring social issues, actions, and performance outcomes. Journal of Business Ethics, 141(3), 621-643. https://doi.org/10.1007/s10551-015-2719-9

Yan, B., Wu, X. H., Ye, B., \& Zhang, Y. W. (2017). Three-level supply chain coordination of fresh agricultural products in the Internet of Things. Industrial Management \& Data Systems, 117(9). https://doi.org/10.1108/IMDS-06-2016$\underline{0245}$

Ye, F., Li, Y., \& Yang, Q. (2018). Resources, conservation, and recycling designing coordination contract for biofuel supply chain in China. Resources, Conservation \& Recycling, 128, 306-314. https://doi.org/10.1016/j.resconrec.2016.11.023

Yin, R. K. (2014). Case Study Research Design and Methods. $5^{\text {th }}$ ed., SAGE Publication. ISBN 978-1-4522-4256-9. 
(C) 2021 by the authors; licensee Growing Science, Canada. This is an open access article distributed under the terms and conditions of the Creative Commons Attribution (CC-BY) license (http://creativecommons.org/licenses/by/4.0/). 